\title{
EDITORIAL
}

\section{Is surgery still the preferred option for coronary revascularisation in diabetics with multivessel coronary disease?}

A Kapur, I S Malik

In patients with diabetes, the choice of optimal revascularisation strategy-bypass surgery or percutaneous coronary intervention - remains controversial

In the UK 2.5 million people have diabetes. Three quarters of all deaths in patients with diabetes are caused by coronary artery disease. It has been projected that $25-30 \%$ of all revascularisations will be in patients with diabetes by 2010. The choice of optimal revascularisation strategy-coronary artery bypass graft (CABG) surgery or percutaneous coronary intervention (PCI)-remains controversial.

CABG is considered preferable in diabetic patients with multivessel coronary artery disease based primarily on post hoc analysis of the BARI study. While some other studies have also performed subgroup analyses in patients with diabetes, in none was that analysis prespecified. In light of recent developments in the field of revascularisation, with the advent of glycoprotein (GP) IIb/IIIa inhibitors, use of stents, and the development of off bypass and minimally invasive surgery, the data available to guide treatment in patients with diabetes are in need of reassessment.

\section{CABG VERSUS PCI: THE MAJOR TRIALS}

Several trials have compared an initial treatment strategy of PCI with a strategy of CABG in patients with multivessel coronary disease.$^{1-6}$ Most of the data currently available relate to comparisons made in the late 1980s and early '90s although several new studies have been published recently. While not identical, each trial randomised patients who were considered suitable for both forms of revascularisation. Results have suggested that there is no difference between the two strategies in terms of mortality, non-fatal MI, and stroke although the rates of additional revascularisation were much higher in the PCI groups. ${ }^{7}$ PCI usually requires a short admission followed by an early return to work, but is associated with a $30 \%$ risk of further revascularisation during the first six months of follow up. Conversely, CABG is more invasive and requires a longer recovery.

authors' affiliations

........................

Correspondence to: Dr Akhil Kapur

Department of Cardiology, National Heart and Lung Institute, Imperial College

School of Medicine,

Hammersmith Hospital

DuCane Road, London

W12 OHS, UK;

a.kapur@ic.ac.uk ventricular dysfunction, and altered platelet function. Moreover, numerous studies have shown that diabetes increases the risk of restenosis after successful PCI. ${ }^{8-10}$ At present, clinicians tend to favour surgery for diabetics requiring coronary revascularisation.

The BARI trial recruited 1829 patients with multivessel disease between 1988 and 1991. ${ }^{3}$ After five years, mortality ( $10.7 \%$ in the CABG arm $v$ $13.7 \%$ in the PCI arm, p = 0.19) and the combined rate of death and non-fatal myocardial infarction (19.6\% CABG $v 21.3 \%$ PCI, $\mathrm{p}=0.84$ ) were similar in the two groups. Although additional revascularisation was required more often in the PCI group ( $8 \%$ CABG $v 54 \%$ PCI, $p<0.001$ ), $69 \%$ of PCI patients avoided CABG during this period and $45 \%$ required only one further PCI. After PCI, patients returned to work an average of five weeks earlier than those undergoing $C A B G$, and there was no difference in long term employment status. ${ }^{11}$

The cohort of 1829 patients in BARI included 353 with diabetes. This subgroup only became a defined group for analysis part way through recruitment. While these patients were not stratified in the randomisation process, their baseline characteristics were similar. The five year mortality was $19.4 \%$ among 180 patients assigned to CABG and $34.5 \%$ among 173 patients assigned to PCI $(\mathrm{p}<0.003)$. Seven year mortality in the PCI group was also higher compared to CABG (23.6\% CABG $v$ $44 \%$ PCI at seven years, $\mathrm{p}=0.001) .{ }^{12}$ Despite this being a post hoc analysis the PCI and CABG arms were well matched and crossover between arms was minimal. However, the outcome of 339 non-randomised diabetics in the registry did not suggest a dramatic advantage of CABG over PCI. ${ }^{8}$ In addition: (1) registry data indicate that only $16 \%$

Abbreviations: ARTS, arterial revascularisation therapies study; BARI, bypass angioplasty revascularisation investigation; BENESTENT; Belgium-Netherlands stent study; CABG, coronary artery bypass graft; CABRI, coronary artery bypass revascularisation investigation; CARDia, coronary artery revascularisation in diabetes; EAST, Emory angioplasty versus surgery trial; EPIC, evaluation of $\mathrm{Ilb} / \mathrm{Ill}$ a platelet receptor antagonist 7E3 in preventing ischemic complications; EPILOG, evaluation of PTCA to improve long-term outcome by c7E3GP Ilb/IIla receptor blockade; EPISTENT, evaluation of platelet GP $\mathrm{Ilb} / \mathrm{Illa}$ inhibitor for stenting; ERACl, Argentine randomized trial of percutaneous transluminal coronary angioplasty versus coronary artery bypass surgery in multivessel disease; GABI, German angioplasty bypass investigation; $\mathrm{GP}$, glycoprotein; $\mathrm{PCl}$, percutaneous coronary intervention; RITA, randomised intervention treatment of angina; SOS, stent or surgery; STRESS, stent restenosis study are specific issues to confront in this gro patients including the problems of small calibre vessels, more extensive distal disease, greater left 
of eligible patients were actually randomised; (2) the PCI arm experienced a $10 \%$ rate of abrupt closure and an $8 \%$ rate of emergency $\mathrm{CABG}$, levels much higher than are seen in current clinical practice. However, in view of the large excess of mortality between the two arms, there is little doubt that diabetics were better off with surgery between 1988 and 1991 .

Evidence from other studies is extremely limited. The CABRI study randomised 1054 patients from 1988 to 1992 to CABG or PCI, with trial end points of mortality and angina at five years. Interim follow up on 1050 patients revealed no difference in one year mortality $(2.7 \%$ CABG $v 3.9 \%$ PCI, $\mathrm{p}=\mathrm{ns}) .{ }^{2}$ In 122 randomised patients who had diabetes, there was a non-significant trend toward better survival in the CABG group at two years (4\% CABG $v 15 \%$ PCI).

The RITA trial randomised 1011 patients from 1988 to 1991 (of whom $45 \%$ had single vessel disease) with a mean follow up of 4.7 years. ${ }^{1}$ The primary end point of death or non-fatal myocardial infarction occurred in 53 CABG patients and 64 PCI patients $(\mathrm{p}=\mathrm{ns}) .{ }^{13}$ Only $62(6 \%)$ out of the 1011 patients recruited had diabetes, precluding meaningful analysis.

In the EAST trial 59 patients of the 392 recruited from 1987 to 1990 had diabetes. Overall, after eight years follow up, mortality was similar in the two treatment groups (17.3\% CABG $v$ $20.7 \%$ PCI, $\mathrm{p}=0.4) .{ }^{14}$ In the diabetic patients, there was a trend towards lower mortality in the surgical group $(24.5 \%$ CABG $v 39.9 \%$ PCI, $\mathrm{p}=0.23$ ). Although repeat revascularisation rates were initially higher in the PCI group, beyond three years the rates were similar in both groups.

Neither the GABI trial, with 43 out of 359 patients with diabetes, nor the Argentine ERACI trial, with 13 out of 127 patients with diabetes, reported separate data pertaining to the diabetics. ${ }^{415}$

\section{PCI VERSUS CABG STUDIES IN THE STENT ERA}

The ARTS trial was based on the premise that coronary artery stenting had improved both short and long term outcomes for coronary angioplasty, making it necessary to re-evaluate the relative merits of CABG versus PCI plus stenting in patients with multivessel disease. The primary composite end point was freedom from major cardiac and cerebrovascular events at one year. In 1205 patients randomised between April 1997 and June 1998, there was no difference in primary end point (91.3\% CABG $v$ 90.6\% PCI, $\mathrm{p}=\mathrm{ns})$. Again, the PCI arm needed more repeat revascularisation procedures $(3.5 \%$ CABG $v 16.8 \%$ PCI, $\mathrm{p}<0.001) .{ }^{16}$

Of the 1205 patients randomised in ARTS, 208 had diabetes. This group was not stratified prospectively, but the diabetic patients in each arm had similar characteristics. The rate of the combined end point of death/cerebrovascular accident/ myocardial infarction was similar in the two arms $(12.5 \%$ CABG, $17 \%$ PCI, $p=n s)$. The requirement for additional revascularisation was higher after PCI (3.1\% CABG $v 25 \%$ PCI, $\mathrm{p}<0.01)$, but was reduced in both diabetic and non-diabetic subgroups compared to trials from the pre-stent era. ${ }^{17}$

ERACI II (Argentine randomised study 1996-8) randomised 450 patients with multivessel disease to undergo either PCI or CABG. At mean follow up of 18.5 months death rates were $3.1 \%$ in PCI patients and $7.5 \%$ in CABG patients $(\mathrm{p}<0.017)$. Requirements for further revascularisation were again higher post-PCI ( $16.8 \%$ PCI $v 4.8 \%$ CABG, $\mathrm{p}<0.002) .{ }^{18}$ As with most previous studies, too few diabetics were randomised for meaningful comment.

The results of the SOS study have not yet been published but preliminary results of this UK based study are available. In nearly 1000 randomised patients mortality was $4.1 \%$ in the PCI arm versus $1.2 \%$ in the CABG group $(\mathrm{p}=\mathrm{ns}) .{ }^{19}$ The higher mortality in the PCI arm was caused by an unexplained excess of cancer deaths. There was no significant difference in the occurrence of myocardial infarction. The rate of repeat revascularisation was again greater after PCI than after CABG $(20 \%$ PCI $v 5.8 \%$ CABG, $\mathrm{p}=0.01$ ). Diabetes was present in 150 of the 1000 patients but no separate data are yet available.

\section{ADJUNCTIVE TREATMENTS IN REVASCULARISATION}

While both CABG and PCI have advanced technically in recent years, the field of coronary angioplasty in its routine practice has changed more substantially than has CABG. The STRESS and BENESTENT trials demonstrated that in selected patients coronary stents reduce the risk of restenosis and subsequent clinical events. ${ }^{2021}$ These benefits may be most pronounced in diabetic patients. ${ }^{9}$ The advent of drug eluting stents may reduce restenosis rates further. ${ }^{22}$

New pharmacological interventions also appear to improve the results of PCI. Several trials have shown that abciximab and other GP IIb/IIIa receptor antagonists improve outcome, especially when combined with stents. ${ }^{23-26}$

Advances in medical treatment, such as aggressive lipid lowering with statins and the use of clopidogrel, may have differential effects post-PCI as opposed to post-CABG. ${ }^{27-28}$ The BARI-2D trial will compare aggressive medical treatment to revascularisation (PCI or CABG) in patients with diabetes, but will not compare PCI to CABG directly.

\section{ADJUNCTIVE ANTIPLATELET TREATMENT IN DIABETIC PATIENTS}

The role of adjunctive periprocedural pharmacotherapy has been examined in several trials, including the EPIC, EPILOG, and EPISTENT trials. In the EPILOG trial, the outcomes of 638 diabetic patients were compared to 2154 non-diabetic patients. ${ }^{29}$ Despite greater comorbidity, diabetic patients treated with abciximab during PCI suffered the same rate of in-hospital death, myocardial infarction, and urgent revascularisation as non-diabetic patients $(7.1 \% \vee 7.5 \%, \mathrm{p}=\mathrm{ns})$. At six months, treatment reduced the composite of death or myocardial infarction to $8.8 \%$ in diabetic patients and $7.4 \%$ in non-diabetics $(p=n s)$, significantly better in both groups when compared to placebo.

In the more recent EPISTENT study, the composite of death, myocardial infarction, or target vessel revascularisation was reduced from $25 \%$ to $13 \%$ (a $48 \%$ reduction, $\mathrm{p}=0.005$ ) in diabetics treated with abciximab and stenting as opposed to stenting alone. ${ }^{30}$ The combined death and myocardial infarction rate was reduced from $16.3 \%$ to $6.8 \%$ at one year, with cardiac event rates in the treated diabetic population being reduced to the level seen in non-diabetic patients. ${ }^{31}$ A pooled analysis of three abciximab trials (EPIC, EPILOG, and EPISTENT) showed that abciximab decreased the one year mortality in diabetics from $4.5 \%$ to $2.5 \%(\mathrm{p}=0.031)$ and in non-diabetic patients from $2.6 \%$ to $1.9 \%(\mathrm{p}=0.1) .{ }^{32}$

The potential role of other GP IIb/IIIa inhibitors such as eptifibatide and tirofiban remains to be determined in diabetics. The use of abciximab and stents among patients with diabetes undergoing PCI appears to abolish the excess risk of such procedures in patients with diabetes. Whether the results achievable with this regimen are comparable to those achieved with modern coronary artery bypass grafting can only be answered by a prospective randomised trial.

\section{CONCLUSION}

An evidence base for the preferred mode of coronary revascularisation (CABG or PCI) in patients with diabetes is lacking. Such data as are available are now more difficult to evaluate in the setting of recent major advances in adjunctive treatment for PCI. The advent of the GP IIb/IIIa inhibitors and drug eluting stents in particular may revolutionise percutaneous intervention in diabetics.

There is an obvious need for a head-to-head trial to establish whether these advances have abolished the outcome gap that was seen in the BARI trial. If one accepts that a higher rate of repeat revascularisation is a reasonable price to pay for a less invasive procedure, then the new trial has to show that "optimal PCI" is not inferior to "up-to-date CABG" in terms of the hard end points of death, non-fatal myocardial infarction, and stroke. The UK based CARDia trial addresses these 
questions for the first time, and will begin recruitment in the near future. It may help provide the answer to the question posed in the title of this editorial.

\section{Authors affiliations}

A Kapur, Department of Cardiology, National Heart and Lung Institute, Imperial College School of Medicine, Hammersmith Hospital, London, UK I S Mailk, Waller Department of Cardiology, St Mary's Hospital, London, UK

\section{REFERENCES}

1 RITA Trial Investigators, Coronary angioplasty versus coronary artery bypass surgery: the Randomized intervention treatment of angina (RITA) trial. Lancet 1993:341:573-80.

2 CABRI Trial Participants. First-year results of CABRI (coronary angioplasty versus bypass revascularisation investigation). Lancet 1995;346: 1 179-84.

3 BARI Investigators. Comparison of coronary bypass surgery with angioplasty in patients with multivessel disease. The bypass angioplasty revascularization investigation (BARI) investigators [erratum appears in $\mathrm{N}$ Engl J Med 1997;336: 147]. N Engl J Med 1996;335:217-25.

4 Hamm CW, Reimers J, Ischinger T, et al. A randomized study of coronary angioplasty compared with bypass surgery in patients with symptomatic multivessel coronary disease. German Angioplasty bypass surgery investigation (GABI). N Engl J Med 1994;331:1037-43.

5 King SB, III, Lembo NJ, Weintraub WS, et al. A randomized trial comparing coronary angioplasty with coronary bypass surgery. Emory angioplasty versus surgery trial (EAST). N Eng J Med 1994;331:1044-50.

6 Rodriguez A, Boullon F, Perez-Balino N, et al. Argentine randomized trial of percutaneous transluminal coronary angioplasty versus coronary artery bypass surgery in multivessel disease (ERACI): in-hospital results and 1-year follow-up. ERACI Group. J Am Coll Cardiol 1993;22:1060-7.

$7 \mathrm{Sim} \mathrm{I}$, Gupta M, McDonald K, et al. A meta-analysis of randomized trials comparing coronary artery bypass grafting with percutaneous transluminal coronary angioplasty in multivessel coronary artery disease. Am J Cardiol 1995;76:1025-9.

8 Detre KM, Guo P, Holubkov R, et al. Coronary revascularization in diabetic patients: a comparison of the randomized and observational components of the bypass angioplasty revascularization investigation (BARI). Circulation 1999:99:633-40.

9 Van Belle E, Bauters C, Leclercq J. Restenosis rates in diabetic patients: a comparison of coronary stenting and balloon angioplasty in native coronary vessels. Circulation 1997;96:1454-60.

10 Aronson D, Bloomgarden Z, Rayfield EJ. Potential mechanisms promoting restenosis in diabetic patients. J Am Coll Cardiol 1996;27:528-35.

11 Hlatky MA, Rogers WJ, Johnstone I, et al. Medical care costs and quality of life after randomization to coronary angioplasty or coronary bypass surgery. Bypass angioplasty revascularization investigation (BARI) investigators. N Engl J Med 1997;336:92-9.

12 BARI Investigators. Seven-year outcome in the bypass angioplasty revascularization investigation (BARI) by treatment and diabetic status. $J$ Am Coll Cardiol 2000;35: 1122-9.

13 Henderson RA, Pocock SJ, Hampton JR. Revascularisation for patients with single vessel disease: results from the randomised intervention treatmet of angina (RITA) trial after 4.7 years. Circulation 1995;92:476.
14 King SB, III, Kosinski AS, Guyton RA, et al. Eight-year mortality in the Emory angioplasty versus surgery trial (EAST). J Am Coll Cardio 2000;35:1116-21

15 Rodriguez A, Mele E, Peyregne E, et al. Three-year follow-up of the Argentine randomized trial of percutaneous transluminal coronary angioplasty versus coronary artery bypass surgery in multivessel disease (ERACI). J Am Coll Cardiol 1996;27: 1 178-84.

16 Serruys PW, Unger F, Sousa JE, et al. Comparison of coronary-artery bypass surgery and stenting for the treatment of multivessel disease. $N$ Engl J Med 2001;344:1117-24.

17 Kornowsky R, Lansky AJ. Current perspectives on interventional treatment strategies in diabetic patients with coronary artery disease. Catheter Cardiovasc Interv 2000;50:245-54

18 Rodriguez A, Bernardi V, Navia J, et al. Argentine randomized study: coronary angioplasty with stenting versus coronary bypass surgery in patients with multiple-vessel disease (ERACI II): 30-day and one-year follow-up results. ERACI II Investigators. J Am Coll Cardiol 2001;37:51-8.

19 SOS Investigators. The stent or surgery (SOS) trial. American College of Cardiology Scientific Sessions 2001.

20 George CJ, Baim DS, Brinker JA, et al. One-year follow-up of the stent restenosis (STRESS I) study. Am J Cardiol 1998:81:860-5.

21 Serruys PW, de Jaegere P, Kiemeneij F, et al. A comparison of balloon-expandable-stent implantation with balloon angioplasty in patients with coronary artery disease. Benestent study group. N Engl J Med 1994;331:489-95

22 Lowe H, Oesterle S, Khachigan L. Coronary in-stent restenosis: current status and future strategies. J Am Coll Cardiol 2001;29:183-93.

23 ESPRIT Investigators. Novel dosing regimen of eptifibatide in planned coronary stent implantation (ESPRIT): a randomised, placebo-controlled trial. The ESPRIT investigators. Enhanced suppression of the platelet Illb/lla receptor with Integrilin therapy. Lancet 2000;356:2037-44.

24 Adgey AA. An overview of the results of clinical trials with glycoprotein Ilb/llla inhibitors. Eur Heart J 1998;19(suppl D):10-21.

25 EPIC investigators. Use of monoclonal antibody directed against the platelet Ilb/llla receptor in high risk coronary angioplasty. N Engl J Med 1998;330:956-61.

26 EPISTENT Investigators. Randomised placebo-controlled and balloon angioplasty controlled trial to assess safety of coronary stenting with use of platelet glycoprotein Ilb/Illa blockade. Lancet 1998;352:87-92.

27 Pitt B, Waters D, Brown WV, et al. Aggressive lipid-lowering therapy compared with angioplasty in stable coronary artery disease. Atorvastatin versus revascularization treatment investigators. N Engl J Med 1999:341:70-6.

28 Bhatt DL, Chew DP, Hirsch AT, et al. Superiority of clopidogrel versus aspirin in patients with prior cardiac surgery. Circulation 2001;103:363-8.

29 Kleiman NS, Lincoff AM, Kereiakes DJ, et al. Diabetes mellitus, glycoprotein Ilb/llla blockade, and heparin: evidence for a complex interaction in a multicenter trial. EPILOG Investigators. Circulation 1998:97:1912-20.

30 Lincoff AM, Tcheng JE, Cabot CF, et al. Marked benefit in diabetic patients treated with stent and abciximab combination: 6 month outcome of the EPISTENT trial [abstract]. J Am Coll Cardiol 1999;133:45A.

31 Marso SP, Lincoff AM, Ellis SG, et al. Optimizing the percutaneous interventional outcomes for patients with diabetes mellitus: results of the EPISTENT (evaluation of platelet llb/llla inhibitor for stenting trial) diabetic substudy. Circulation 1999;100:2477-84.

32 Bhatt DL, Marso SP, Lincoff AM, et al. Abciximab reduces mortality in diabetics following percutaneous coronary intervention. J Am Coll Cardiol 2000;35:922-8.

\section{STAMPS IN CARDIOLOGY}

\section{Werner Forssmann}

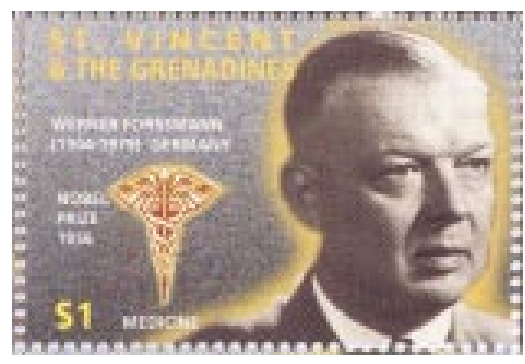

Jerner Forssmann (1904-1979) was the pioneer of cardiac catheterisation in man. In 1929, at the age of 25, while doing his surgical training at Eberswalde, a small town near Berlin, he introduced a ureteral catheter into his own right atrium. Using a mirror he advanced the catheter under fluoroscopic control and then climbed the stairs to the $x$ ray department where a chest film was taken. Forssmann had two objects in mind. Firstly to use this technique in emergencies to administer drugs directly into the heart, and secondly "to study the heart and for diagnosis". Later he catheterised his own heart on six more occasions. He also injected contrast material, Uroselectan, in 1931 in an attempt to produce an angiocardiogram. By 1932 pulmonary angiography using a catheter in the right atrium had been done in Lisbon, Paris, and Buenos Aires.

Cardiac catheterisation made it possible to measure the cardiac output using the Fick principle and this important advance was first made in Prague in 1930. The development of Forssman's technique owed much to the work in New York of André Cournand and Dickinson Richards and together with Forssmann they were the joint recipients of the Nobel Prize for physiology or medicine in 1956. Werner Forssmann ended his career as chief surgeon to the Evangelical Hospital in Dusseldorf.

St Vincent and the Grenadines issued a set of 48 \$1.00 stamps in 1995 to commemorate the centenary of the Nobel Prize Trust Fund. These were issued in sheetlets of 12 with each stamp in the four sheetlets depicting a different recipient of a Nobel Prize. Eight of the stamps celebrated Nobel Prize winners for medicine including Konrad Lorenz, Ivan Pavlov, and Werner Forssmann. 